\title{
DO IMPRESSO AO DIGITAL: REFLEXÕES ACERCA DE RECURSOS PEDAGÓGICOS NUMA ESCOLA VULNERÁVEL
}

\section{FROM PRINTED TO DIGITAL: THE USE OF PEDAGOGICAL RESOURCES IN SCIENCE CLASSES IN A VULNERABLE SCHOOL.}

\author{
PINTO, Sabrine Lino ${ }^{1}$ \\ NERY, Aline Silva Dejosi ${ }^{2}$ \\ VERMELHO, Sônia Cristina ${ }^{3}$
}

\begin{abstract}
RESUMO
Apresenta reflexões e resultado de pesquisa sobre o uso da biblioteca como espaço de articulação dos conteúdos trabalhados em sala de aula e na rede social Facebook como ferramenta pedagógica para a construção do conhecimento científico num contexto de vulnerabilidade social com base em Freire (1989), Adorno e Horkheimer (1947), Abramovay et al (2002), Oliveira (2002) e Silva (2010). Trata-se de uma pesquisa qualitativa, no modo participante, apresentando resultados de um questionário realizado com alunos do ensino fundamental cujo objetivo foi apurar seus hábitos de leitura e usos da biblioteca, da internet e da rede social. Os resultados indicaram que a biblioteca se apresenta como espaço potencial na escola e para os professores utilizarem em suas práticas pedagógicas. Quanto à internet foi apurado que um número significativo de alunos faz uso, sendo que apenas alguns participavam de página criada no Facebook por meio de visualizações, comentários e curtidas nas postagens relacionadas às Ciências.
\end{abstract}

PalaVRas-chave: biblioteca escolar; ensino de ciências; Facebook; vulnerável.

\section{ABSTRACT}

It presents reflections on the use of the library as a space for articulating content worked in the classroom and the social network Facebook as a pedagogical tool for the construction of scientific knowledge in a context of social vulnerability, based on Freire (1989), Adorno and Horkheimer (1947), Abramovay et al (2002), Oliveira (2002) and

1 Universidade Federal do Rio de Janeiro - UFRJ. Rio de Janeiro, RJ, Brasil. Instituto Federal do Espírito Santo - IFES. Vitória, ES, Brasil. ORCID: http://orcid.org/0000-0002-8363-0328 e-mail: brinevix@gmail.com 2 Universidade Federal do Rio de Janeiro - UFRJ / Programa de Pós-graduação do Instituto Nutes de Educação em Ciências e Saúde - PPGECS. Rio de Janeiro, RJ, Brasil. ORCID: http://orcid.org/0000-00031399-5679 e-mail: alinesnery@gmail.com

3 Universidade Federal do Rio de Janeiro - UFRJ / Programa de Pós-graduação do Instituto Nutes de Educação em Ciências e Saúde - PPGECS. Rio de Janeiro, RJ, Brasil. ORCID: http://orcid.org/0000-00032205-8070 e-mail: cristina.vermelho@gmail.com

DO IMPRESSO AO DIGITAL: REFLEXÕES ACERCA DE RECURSOS PEDAGÓGICOS NUMA ESCOLA VULNERÁVEL 
DOI: $10.12957 / \mathrm{e}-\mathrm{mosaicos} .2021 .49852$

Silva (2010). It is a qualitative research, in the participant mode, presenting results of a questionnaire carried out with elementary school students, whose objective was to ascertain their reading habits and uses of the library, the internet and the social network. The results proved that the library presents itself as a potential space in the school and for teachers to use in their pedagogical practices. And, as for the internet, it was found that a significant number of students make use of it, with only 35 students participating in a page created on Facebook through views, comments and likes in posts related to Science.

KEYwORDS: school library; science teaching; Facebook; vulnerable.

\section{INTRODUÇÃO}

Um dos objetivos do ensino de ciências atualmente é promover o interesse dos alunos acerca da importância dos conteúdos científicos na sua formação como cidadãos críticos, para que possam compreender os problemas gerados pelo modelo produtivo e social marcadamente consumista e excludente (CHASSOT (2011); MARCUSE, 1973). Nesse sentido, a introdução de recursos no ensino de ciências pode se apresentar como uma ferramenta para auxiliar os professores de ciências no processo de ensinoaprendizagem de uma forma prazerosa e lúdica, porém, condizente com os conteúdos curriculares. Entre inúmeros recursos, a opção foi trabalhar com o espaço da biblioteca, mais especificamente, a leitura, e as redes sociais, em especial, o Facebook.

Ao contrário de como é comumente conhecida, a biblioteca não é somente um espaço onde são armazenados livros, pois sua principal função é viabilizar o acesso à informação, nos mais variados suportes. Porém, em um mundo com constantes mudanças tecnológicas no qual novas necessidades surgem e os velhos paradigmas se alteram, a biblioteca precisa se diversificar a cada dia, inovando e se aliando à tecnologia, para atender aos anseios dos usuários. Nessa perspectiva, o hábito da leitura ajuda as pessoas a serem mais críticas enquanto cidadãos. Ela é peça-chave para a alfabetização, a qual, segundo Freire (1989, p. 19), é entendida "como ato de conhecimento, como ato criador e como ato político" e se constituiu "um esforço de leitura do mundo e da palavra", no qual o texto se relaciona diretamente com o contexto. Dessa forma, o hábito da leitura é primordial no processo de formação de homens e mulheres como cidadãos críticos.

A inclusão da informática com o uso dos computadores nos currículos escolares e na educação ocorre desde os anos 1970 (OLIVEIRA; OLIVEIRA, 2017). O Facebook, ao ser utilizado como uma ferramenta de aprendizagem, permite ao professor ressignificar seu modo de ensinar de forma mais participativa e mútua, seja a distância ou presencial, além de facilitar a mediação pedagógica e a interação dos alunos. Também abre a possibilidade de amplificação quanto aos questionamentos e discussões de informações. 
DOI: $10.12957 / \mathrm{e}-\mathrm{mosaicos} .2021 .49852$

O presente estudo foi parte de uma pesquisa longitudinal na modalidade de pesquisa participante, intitulada "Educação em Ciências: estudo das mediações com jovens em situação de vulnerabilidade social", que foi desenvolvida pelo Grupo de Pesquisa Formação, Política e Trabalho Humano na Perspectiva das Teorias Críticas em uma escola municipal de ensino fundamental localizada em Manguinhos na cidade do Rio de Janeiro. Se trata de uma pesquisa que compreendeu o desenvolvimento de atividades com objetos de estudo variados descritos no breve cronograma a seguir. Dando início em agosto de 2015 pela coordenadora da pesquisa e uma mestranda, foram realizadas oficinas de fotografia com os alunos, num processo preliminar de aproximação com a escola. Nos anos de 2016 e 2017, com o acompanhamento de 4 mestrandas e 1 doutoranda, foram realizadas atividades com a educação e saúde na escola, algumas com a participação de professores e outras no formato de oficinas com alunos. Concomitante a isso, $\mathrm{m} 2017$ foram iniciados os trabalhos com a rede social Facebook, sob a supervisão de uma mestranda, e com atividades na biblioteca, sob a supervisão de uma doutoranda, os que perduraram até o final do ano de 2018. Em 2019, ocorreram atividades coordenadas por uma mestranda no laboratório de ciências, dando finalização ao projeto. Importante salientar que todas as atividades desenvolvidas foram previamente discutidas com a direção da escola e com outros interessados.

Este trabalho, em especial, representou a fase inicial dos estudos que tinham como objeto o uso da biblioteca e da Internet como espaços educativos. Ele apresenta os resultados de um questionário que foi respondido por alunos de uma escola localizada em um ambiente socialmente vulnerável, visando conhecer seus hábitos de leitura e uso de redes sociais, de modo a identificar as potencialidades destes componentes como ferramentas de apoio para o ensino e aprendizagem da ciência com uma perspectiva crítica.

\section{FUNDAMENTAÇÃO TEÓRICA}

\section{O contexto Vulnerável de Manguinhos}

Nesta pesquisa, os participantes foram os alunos e professores, sendo que os primeiros são, em geral, caracterizados como crianças em situação de vulnerabilidade social, não só em sentido material, mas sobretudo, afetivo, muitas vezes, marginalizados, oprimidos e em constante contato com a violência. Este contexto é levado em conta durante o estudo, bem como suas realidades, hábitos e costumes, ou seja, a cultura desse grupo como fator de impacto.

De acordo com Rado e Boneti (2009), a vulnerabilidade social, ao mesmo tempo que oportuniza ter conhecimento do cenário global sobre as condições de vida dos menos 
DOI: $10.12957 / \mathrm{e}-\mathrm{mosaicos} .2021 .49852$

afortunados, quando se refere à insegurança, à incerteza e à exposição a riscos causados por fenômenos socioeconômicos ou a privação ou impedimento ao alcance de insumos básicos, também leva em consideração a disponibilidade de recursos e estratégias para que estes indivíduos enfrentem as dificuldades que Ihes sobrevém. A "condição de vulnerabilidade" assemelhada como uma marca da diferença está vinculada com a situação de pobreza, que é o principal condutor dos indivíduos à marginalidade, agregada com elementos tais como, modos de comportamento, territórios de circulação e moradia, distintas práticas cotidianas não ideais, que se apresentam como verdadeiros desafios e dilemas aos manuais e saberes dos especialistas (RADO; BONETI, 2009).

A escassez ou limitação na disponibilidade dos insumos como educação, trabalho, saúde, lazer e cultura é um aspecto perverso da vulnerabilidade social que "diminui as chances de aquisição e aperfeiçoamento desses recursos fundamentais para que os jovens aproveitem as oportunidades oferecidas pelo Estado, pelo mercado e pela sociedade para ascender socialmente" (ABRAMOVAY et al, 2002, p. 33). Nesta perspectiva, o jovem em situação de vulnerabilidade social possui a característica de estar desprovido de forma parcial ou integral dos recursos materiais e simbólicos, não tendo acesso às estratégias para usar esses recursos.

\section{A IMPORTÂNCIA DA LEITURA E DAS ARTICULAÇõES DA BIBLIOTECA ESCOLAR COM A SALA DE AULA PARA O ENSINO DE CIÊNCIAS}

Um dos aspectos abordados neste estudo teve como intuito suscitar o interesse dos alunos por meio das mediações pedagógicas utilizadas por professores e do profissional bibliotecário na biblioteca como espaço potencial de articulação dos conteúdos trabalhados em sala de aula. O enfoque foi dado à disciplina de ciências, do ensino fundamental visando à promoção de experiências educativas para a construção do conhecimento científico num contexto de vulnerabilidade social e, assim, poder contribuir para uma educação emancipadora.

Um levantamento realizado em outubro de 2017 pelo Movimento Todos pela Educação previa que, para que a determinação da Lei 12.244, de maio de 2010 (MINISTÉRIO DA EDUCAÇÃO, 2010), que estabelecia a obrigatoriedade da existência de um acervo de pelo menos um livro por aluno em cada instituição de ensino do País em redes públicas e privadas, fosse cumprida, 81 bibliotecas deveriam ter sido construídas por dia até o ano de 2020 (GLOBO.COM, 2017). E, mais ainda, foi exigida também a existência de pelo menos um bibliotecário em cada biblioteca. Tais metas não foram atingidas, expondo-se assim, que a educação não é prioridade no Brasil, como no caso desta escola em Manguinhos, cuja biblioteca estava em desuso, sendo reaberta por ocasião da pesquisa. 
DOI: $10.12957 / \mathrm{e}-\mathrm{mosaicos} .2021 .49852$

O hábito da leitura, tanto na sala de aula quanto nas bibliotecas das escolas, cumpre um papel fundamental para a formação do leitor que, por conseguinte, acaba por influenciar também na formação escolar de qualidade. A biblioteca neste contexto se insere como um local que ainda preserva a função de dar acesso às informações, espaço em que pode mediar a produção do conhecimento. A oportunidade de ler tem como horizonte a autonomia dos alunos, o contato com outras realidades e conhecimentos e, também, com a linguagem científica. Nesse processo, no início do século XXI, as mídias assumiram uma dimensão mais de prazer, enquanto as bibliotecas, uma dimensão prioritariamente educativa e, por isso, este estudo procurou contemplar tanto o uso, 0 gosto e o interesse dos alunos pela biblioteca e pelas redes sociais, pois, acredita-se que ambas podem "andar juntas" e serem aliadas para a formação do indivíduo e no processo de ensino e aprendizagem.

\section{A UTILIZAÇÃo dA REDE SOCIAL FACEBOOK COMO FERRAMENTA PEDAGóGICA DE APOIO Às AULAS DE CiÊnCIAS PARA ALUNOS DE CONTEXTO VULNERÁVEL}

Com o avanço tecnológico, os relacionamentos passaram a ocorrer pela internet e assim surgiram as redes sociais digitais, possibilitando às pessoas trocar informações, compartilhar experiências, colaborar com projetos, participar no aprendizado coletivo, fortalecer os laços entre seus membros e aumentar o poder de decisão do grupo (SILVA, 2010). Dessa forma, as redes sociais digitais apresentam-se hoje como um recurso com potencial ao se dialogar acerca da importância dos movimentos sociais, políticos, econômicos e científicos associados às experiências do cotidiano com os alunos. Pode-se levantar, por meio das redes sociais, assuntos relacionados ao ensino de ciências com questões ligadas a problemas éticos, religiosos, ideológicos, culturais, étnicos, além de realizar debates como a educação ambiental, saúde, sexualidade, entre outros temas dentro do Facebook.

Essa ação de trazer a rede social para dinamizar a aprendizagem exige que os usuários tenham acesso a um aparelho celular ou um computador para poderem se conectar a uma plataforma tecnológica e à internet, fato que envolve lidar com as suas contradições sociais e econômicas, principalmente por se tratar de jovens em situação de pobreza, o que pode ser desafiador, conforme afirmado por Oliveira (2002, p. 43) quando cita que:

Para o sistema educativo e seus agentes reside aqui o grande desafio: sendo continuamente adquiridas. A habilidade de distinguir entre informações importantes e não importantes é vital. A habilidade de reconhecer quando novas informações alteram o panorama baseado em decisões tomadas ontem, também é crítica. [...] construção colaborativa de 
DOI: $10.12957 / \mathrm{e}-\mathrm{mosaicos} .2021 .49852$

saberes, na abertura aos contextos sociais e culturais, à diversidade dos alunos, aos seus conhecimentos, experimentações e interesses.

Nas visitas iniciais à escola localizada em Manguinhos na cidade do Rio de Janeiro foi observado que nas aulas de ciências das turmas de ensino fundamental dos turnos da manhã e da tarde durante o período letivo de 2017 havia um completo desinteresse dos alunos pela disciplina de Ciências.

A partir disso, buscou-se compreender os processos que estão envolvidos no uso das redes sociais como possibilidade metodológica no Ensino fundamental da Educação Básica da escola. Essa estratégia pode ser capaz de gerar mais interesse, questionamentos e reflexões nos alunos sobre temas das ciências: Os alunos veem o Facebook com um olhar como uma ferramenta pedagógica? Como os estudantes se apropriam deste recurso? Por meio das redes sociais os estudantes teriam mais interesse em pesquisar assuntos da disciplina de ciências?

Com base nesse levantamento, foi criada uma página no Facebook, na qual, foram trabalhados temas e perguntas ligadas ao currículo e com as estratégias pedagógicas que melhor se adequariam a esses conteúdos e recursos para proporcionar aos alunos experiências que levassem à conscientização sobre as questões internas e externas à escola, para que compreendessem a sociedade atual, condizente com a faixa etária e que Ihes trouxessem respostas aos grandes dilemas com se deparam cotidianamente.

\section{Procedimentos metodológicos}

Essa pesquisa se caracteriza como Pesquisa Participante, do tipo pesquisaformação, dando mais atenção aos aspectos subjetivos da experiência e do comportamento humano. Por isso, foram realizadas várias incursões no território educativo com o objetivo de conhecer e acompanhar vividamente o cotidiano da escola e do seu corpo docente e discente, cujo objetivo foi investigar o uso da biblioteca e da rede social Facebook como alternativas metodológicas nas turmas de ensino fundamental da escola nas aulas de ciências e refletir sobre sua capacidade de estimular o interesse e o pensamento crítico dos estudantes frente a diversos materiais midiáticos e tecnológicos sobre educação em ciências.

No caso deste trabalho em específico, o objetivo foi apresentar como um levantamento inicial, a primeira etapa desta pesquisa, que abrangeu a utilização de um questionário como instrumento de coleta de dados direcionado aos alunos. Os resultados permitiram não só conhecer o seu perfil, hábitos e interesses de leitura, frequência à biblioteca e também hábitos, gostos, interesse e realidade quanto ao uso das redes sociais, bem como, constatar limitações, lacunas e fatores positivos no que tange as 
DOI: $10.12957 /$ e-mosaicos.2021.49852

representações e a importância destes recursos no processo de formação destes alunos. Conhecer estes dados cumpriram um papel fundamental para a realização e posterior finalização da pesquisa, uma vez que direcionaram e ajustaram certas ações durante essas incursões em campo.

O questionário foi destinado a todos os alunos dos turnos matutino e vespertino matriculados na escola, do qual foi obtido um total de 524 respondentes, sendo este um instrumento que possibilitou fazer uma análise do perfil dos estudantes em caráter exploratório e descritivo, resultando na construção de indicadores (FERREIRA, 2002; SILVA; HAYASHI; HAYASHI, 2011). Esses dados foram inseridos no software de análise estatística Sphinx Léxica, versão 5.1 que permitiu a realização de análises quantitativas e qualitativas por meio de análise do conteúdo a partir de categorias analíticas e os testes de hipótese a partir da quantificação das categorias analíticas.

Quanto ao perfil dos estudantes, 303 eram do sexo feminino e 221 do sexo masculino, o que equivale a $57,80 \%$ e $42,20 \%$, respectivamente. Os alunos do sexto ano foram os que mais responderam, 144 , o que equivale a $27,50 \%$ do total, seguido dos alunos do sétimo ano, com 124 participantes, ou seja, 23,70\%, 64 alunos do oitavo ano, equivalente a $12,20 \%$, 59 ou $11,30 \%$ de turmas especiais, vindo na sequência, 45 alunos do nono ano, representando $8,60 \%$, os do quinto ano com 42 ou $8 \%$, depois os do quarto ano com 29 alunos que responderam, ou seja, 5,50\% e, por último, 17 alunos do terceiro ano o que equivale a $3,20 \%$ do total de respondentes.

Quanto a faixa etária, vale destacar os alunos com 13 anos que foram a maioria dos respondentes e correspondem a 129 , o equivalente a $24,60 \%$ do total, seguido pelos alunos com 12 anos, correspondente a 19,10\%, 88 alunos com 11 anos o que equivale a $16,80 \%$, 74 alunos com 14 anos, representando $14,10 \%$ do total e 55 alunos com 15 anos, ou seja, 10,50\%. As demais idades $(9,10,16,17$ e 18) apresentaram um quantitativo inferior a 25 alunos, ou seja, menos de $4,8 \%$ do total, conforme pode ser observado no Quadro 1.

Quadro 1: Relação entre a faixa etária e a turma

\begin{tabular}{|c|c|c|c|c|c|c|c|c|c|}
\hline \multirow{2}{*}{ Idade } & \multicolumn{7}{|c|}{ Turma } & \multirow{2}{*}{ Total } \\
\cline { 2 - 9 } & $\mathbf{3 0}$ & $\mathbf{4 0}$ & $\mathbf{5 0}$ & $\mathbf{6 0}$ & $\mathbf{7 0}$ & $\mathbf{8 0}$ & $\mathbf{9 0}$ & $\begin{array}{c}\text { Turmas } \\
\text { Especiais }\end{array}$ & \\
\hline 8 & 1 & 0 & 0 & 0 & 0 & 0 & 0 & 0 & 1 \\
\hline 9 & 5 & 16 & 0 & 0 & 0 & 0 & 0 & 0 & 21 \\
\hline 10 & 2 & 6 & 11 & 6 & 0 & 0 & 0 & 0 & 25 \\
\hline
\end{tabular}


DOI: $10.12957 /$ e-mosaicos.2021.49852

\begin{tabular}{|c|c|c|c|c|c|c|c|c|c|}
\hline 11 & 4 & 0 & 10 & 71 & 1 & 0 & 0 & 2 & 88 \\
\hline 12 & 3 & 1 & 6 & 39 & 41 & 1 & 0 & 9 & $\mathbf{1 0 0}$ \\
\hline 13 & 0 & 0 & 9 & 22 & 38 & 39 & 3 & 18 & $\mathbf{1 2 9}$ \\
\hline 14 & 0 & 0 & 3 & 5 & 25 & 15 & 18 & 8 & 74 \\
\hline 15 & 2 & 0 & 0 & 1 & 13 & 7 & 18 & 14 & 55 \\
\hline 16 & 0 & 0 & 3 & 0 & 3 & 1 & 5 & 7 & 19 \\
\hline 17 & 0 & 3 & 0 & 0 & 1 & 1 & 1 & 1 & 7 \\
\hline 18 & 0 & 0 & 0 & 0 & 1 & 0 & 0 & 0 & 1 \\
\hline 19 & 0 & 0 & 0 & 0 & 1 & 0 & 0 & 0 & 1 \\
\hline Não resposta & 0 & 3 & 0 & 0 & 0 & 0 & 0 & 0 & 3 \\
\hline Total & 17 & 29 & 42 & $\mathbf{1 4 4}$ & $\mathbf{1 2 4}$ & 64 & 45 & 59 & 524 \\
\hline
\end{tabular}

Fonte: Elaborado pelas autoras

Observou-se que há uma variação bem significativa na faixa etária dos alunos, entre a maior idade, que foi de 19 anos e a menor idade, 8 anos, embora seja apenas 1 aluno para cada idade. Também, observou-se que foi a faixa etária de 11 a 15 anos a que mais apresentou alunos que responderam, confirmando que essa idade é a mais apropriada para os alunos do segundo ciclo do ensino fundamental, com exceção apenas dos alunos com 15 anos, que, via de regra deveriam estar cursando o primeiro ano do ensino médio. Tal fato comprova que esses alunos encontram-se fora da faixa de idade adequada para frequentar essa etapa educacional, conforme corroborado pelos dados do Censo Escolar da Educação Básica de 2016 (Instituto Nacional de Estudos e Pesquisas Educacionais Anísio Teixeira, 2017), que revelou serem altas as taxas de não aprovação nas séries introdutórias dos anos finais: $19,2 \%$ no $6^{\circ}$ ano e $17,2 \%$ no 70 ano. A relação entre as taxas de não aprovação e a distorção idade $\mathrm{x}$ série, segundo o Censo, apresentou, entre os dados que se destacam, um percentual de $28 \%$ no $6^{\circ}$ ano, $27,3 \%$ no 70 ano e $26,2 \%$ no $8^{\circ}$ ano, o que corresponde a quase $30 \%$ do total de alunos matriculados nestas séries. 
DOI: $10.12957 / \mathrm{e}-\mathrm{mosaicos} .2021 .49852$

\section{Resultados e discussão}

São apresentados inicialmente os resultados obtidos com as respostas relacionadas à biblioteca e à leitura e, posteriormente, os resultados obtidos com as respostas relacionadas à internet e às redes sociais.

Acerca dos hábitos e gostos sobre o uso da biblioteca e leitura dos participantes da pesquisa, dos 524 respondentes, 496 tinham acesso à internet, ou seja, $94,70 \%$ do total. Esta informação é importante, visto que o acesso e uso dessa ferramenta impacta de forma direta o hábito e gosto de leitura dos alunos e a sua frequência à biblioteca, conforme pode ser constatado na questão seguinte. Observou-se que mais da metade dos alunos que responderam, ou seja, 292 alunos e alunas gostavam de frequentar a biblioteca, o que equivale a $55,70 \%$, contra $38,20 \%$ (200) que não gostavam. Este dado é crucial para a pesquisa, pois, como foi apurado na tabela anterior, quase todos os alunos tinham acesso à internet e, mesmo assim, mais da metade gostava de frequentar a biblioteca. Também deve ser considerado o fato de que a biblioteca da escola estava fechada há mais de um ano por ocasião da pesquisa e não dispunha de um acervo muito novo e nem de uma infraestrutura com qualidade e variedade que pudesse ser mais atrativa aos alunos.

Outra questão levantada revelou que 274 alunos, ou seja, 52,30\%, não frequentaram ou frequentavam outra biblioteca. Saber disso demonstra o quão essencial é a biblioteca da escola para esses alunos, principalmente para os que gostavam de frequentá-la, a qual reafirma a sua função como espaço de socialização e de contribuição para o conhecimento. $\mathrm{E}$, nesse caso, única e imprescindível para a formação desses participantes da pesquisa.

Quando perguntados acerca da influência sobre o hábito da leitura, o intuito foi identificar o papel do professor como influenciador dos hábitos de leitura dos alunos. Um dado positivo foi que 106 alunos, ou seja, 20,20\%, responderam que um dos motivos que os faziam escolher um livro para ler eram as dicas dos professores; outros 133 alunos $(25,40 \%)$ afirmaram que os professores eram os maiores incentivadores ou influenciadores do hábito de leitura. Considerável foi a indicação das mães como as maiores influenciadoras, como responderam 290 ou $55,30 \%$ dos alunos. Foi interessante também descobrir que a própria pesquisadora foi citada em 3 respostas como outra pessoa que influencia, algo que surpreendeu também, levando-se em consideração que a sua presença ali era ainda recente, mas que se revelou importante naquele espaço e para aqueles alunos. Quando se leva em consideração que o fato de ser bibliotecária, isso demonstra também o quão essencial é este profissional para a escola no sentido de colaborar para a educação de modo geral, para os professores em suas práticas e articulações e em especial para os alunos na sua formação. 
DOI: $10.12957 / \mathrm{e}-\mathrm{mosaicos} .2021 .49852$

As respostas apontadas no Gráfico 1 foram inesperadas uma vez que havia uma crença errônea de que os quesitos negativos alistados, tais como, que a leitura é uma obrigação, toma muito tempo, é cansativa, não significa nada e é difícil, teriam um quantitativo maior de respostas. Todavia, foram os menos apontados pelos alunos, ficando todos no patamar abaixo de $7,4 \%$ do total dos questionários respondidos. A resposta que dizia que a "leitura traz conhecimento" foi a mais indicada pelos alunos com 346 indicações, o que equivale a $66 \%$ do total, seguido por 273 , ou seja, $52,10 \%$ que indicaram que a "leitura facilita a aprendizagem na escola", apontando para o fato de que os alunos sabiam da importância da leitura para a sua formação. As opções "Vai me ajudar a ser alguém na vida", com 245 respostas (46,80\%) e "Me ensina a viver melhor", indicado por $158(30,20 \%)$ demonstraram que os alunos acreditavam que a leitura tem relação com seu futuro profissional e na sua vida.

Gráfico 1: Distribuição de frequência quanto ao significado da leitura para os estudantes

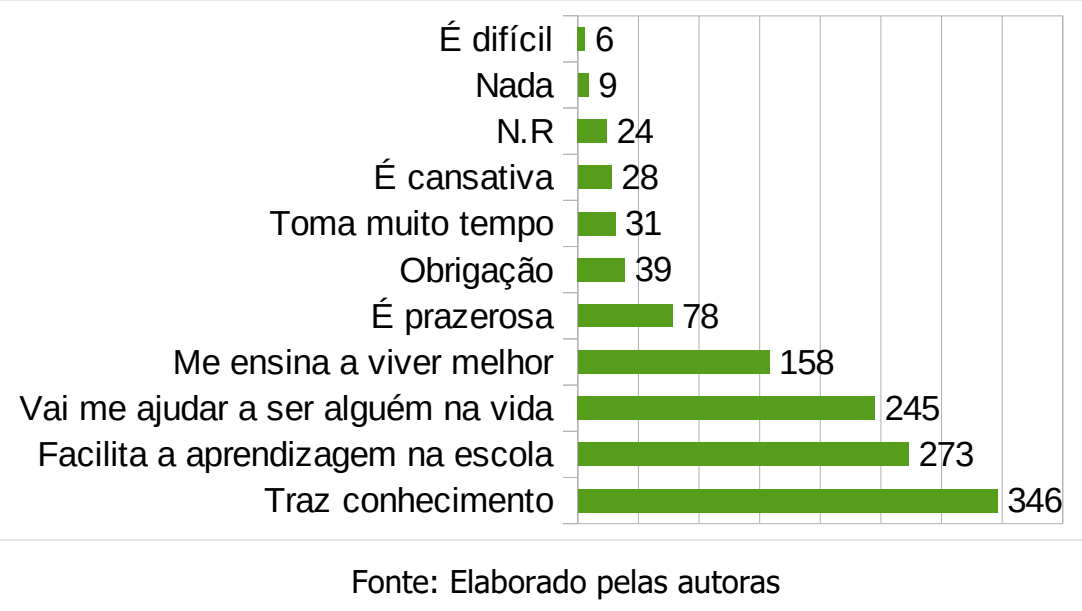

A biblioteca era vista pela maioria dos respondentes, indicado por 379 (72,30\%) alunos, como um local exclusivamente destinado para estudar ou pesquisar, caracterizando-a como um lugar próprio do espaço escolar e, assim sendo, local destinado a atividades escolares de leitura, pesquisa e escrita. Todavia, 150 alunos, ou seja, $28,60 \%$, atribuíam a biblioteca a característica de ser um espaço destinado ao lazer ou para passar o tempo, fato inclusive comprovado pela pesquisadora, quando observou que muitos alunos frequentavam a biblioteca em momentos de tempo vago de aula ou quando iam para brincar com jogos ou teatro, situações que se relacionam em muito com um viés de ação cultural que a biblioteca possui. Também, o fato de que 49, ou seja, 9,40\% dos alunos responderem que a biblioteca é um local onde se pode realizar palestras, cursos ou oficinas sinaliza esse viés cultural, no qual a biblioteca se assume como um ponto de 
DOI: $10.12957 / \mathrm{e}-\mathrm{mosaicos} .2021 .49852$

encontro para tratar assuntos pertinentes às necessidades de um grupo e, no caso da escola, como um contributo para a formação extracurricular da comunidade escolar.

Diante do exposto, esses dados revelaram resultados já esperados e outros surpreendentes, mas o que se pode sintetizar é que a biblioteca se apresenta como um local de excelência dentro da escola, seja para estudar, como local de ação cultural ou espaço potencial para os professores utilizarem em suas práticas pedagógicas. Por isso, ficou constatado o quão necessário é dispor de um profissional bibliotecário que possa gerir e manter esse espaço no sentido de contribuir para a formação dos alunos, em especial a alfabetização cientifica critica nos moldes de uma educação emancipadora de palavra mundo, como atesta Paulo Freire (1989).

O largo uso das mídias, entre elas, a televisão e a internet, indica a forte influência que a indústria cultural (ADORNO; HORKHEIMER, 1947) tem sobre os jovens e crianças, ditando modelos de vida tão distantes da realidade e muitas vezes, fúteis, desconectados da busca pela transformação de seu contexto e superação das dificuldades que sobrevém a estes que se encontram em situação de vulnerabilidade social. E, nesse contexto, a biblioteca, como espaço social e democrático, se apresenta como uma ferramenta que promove uma formação crítica com potencial de desvelar a falsa consciência difundida pelo sistema capitalista que massacra os indefesos da maioria dos povos no mundo.

Embora as fragilidades e os obstáculos sejam muitos, o fato de oportunizar ao aluno um espaço que promova a articulação de práticas pedagógicas com os conteúdos trabalhados em sala de aula, mediante o favorecimento do hábito de leitura como apropriação do mundo, a biblioteca se torna um diferencial que permite ir além do ensino tradicional e mecânico. Para os alunos, além da extensão da sala de aula, a biblioteca se apresenta como espaço de socialização e como uma possibilidade para o acesso ao conhecimento e ao prazer do hábito da leitura. Para os professores é uma oportunidade para o desenvolvimento de práticas e atividades que possibilitem contribuir para a formação emancipadora dos alunos e pensar em maneiras diferenciadas de favorecer o pensamento reflexivo, crítico e revolucionário. Portanto, a existência e manutenção da biblioteca como um local de excelência dentro do espaço escolar pode não só servir para uma educação comprometida com a realidade dos alunos, em especial para aqueles em situação de vulnerabilidade social, para que exercite a sua curiosidade e imaginação, para que 0 alimente de sonhos, devolvendo-lhe o brilho no olhar, como também pode contribuir para a sua ressignificação no contexto escolar.

Acerca dos hábitos e gostos sobre o uso da internet e das redes sociais, as respostas foram imprevistas, pois, era esperado que, por ser tratarem de jovens em situação de vulnerabilidade, eles não teriam acesso próprio à internet, quando o resultado nos mostrou exatamente o oposto, ou seja, $94,70 \%$, ou seja, 496 respondentes tinham 
DOI: $10.12957 / \mathrm{e}-\mathrm{mosaicos} .2021 .49852$

acesso próprio a alguma rede, e somente 28 alunos, o que corresponde a 5,30\%, informaram não ter acesso.

Referente à distribuição de frequência quanto ao local em que mais acessa a internet, foi interessante que $80,50 \%$ dos estudantes responderam ter acesso pelo próprio celular, ficando o computador em segundo lugar com apenas 20,40\%, conforme apresentado no Gráfico 2. Apesar de 2,30\% dos estudantes citarem que tinham acesso à internet na escola, aferiu-se que os alunos entenderam sobre seu acesso à internet dentro do ambiente escolar por meios próprios, já que o laboratório de informática não estava acessível a eles. No Gráfico 2 a questão era de múltipla escolha, portanto, o total de frequência foi superior a quantidade de questionários aplicados.

Gráfico 2: Distribuição de frequência quanto ao local em que mais acessa a internet (\%)
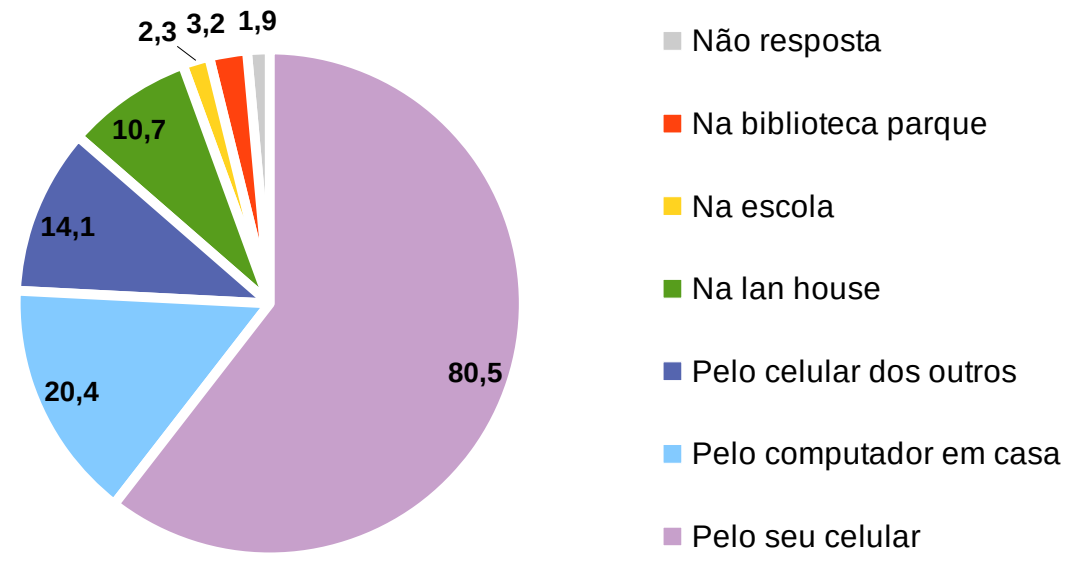

Fonte: Elaborado pelas autoras

Em outra questão foi indagado o que eles mais gostavam de fazer na internet. A opção de ver filmes e vídeos em sites como Youtube e usar as redes sociais como Facebook, Twitter, Instagram, entre outros, ficaram em um número bem próximo, obtendo $67,60 \%$ e $64,90 \%$ das respostas respectivamente. Participar de jogos online ficou em terceiro lugar, com 35,50\% das intenções, ficando a opção de trabalhos escolares em 50 lugar com $26,70 \%$ do total de respostas, dado muito importante por se apresentar como um meio de mostrar aos alunos que a rede social digital pode ser usada como um meio pedagógico, além de mostrar que os alunos se interessam pela tecnologia.

No Gráfico 3 estão expostos os dados em relação ao uso das redes sociais: 454 alunos $(86,60 \%)$ responderam que tinham o perfil próprio na rede social digital Facebook, o Instagram foi indicado por $36,10 \%$ dos alunos e o Twitter por $27,10 \%$ dos alunos. 
DOI: $10.12957 / \mathrm{e}-\mathrm{mosaicos} .2021 .49852$

Quanto à frequência de acesso à rede social, 60,50\% responderam que acessavam diariamente seu perfil no Facebook, 37,80\% responderam que não acessavam diariamente e 1,70\%, preferiram não responder à questão. A distribuição de frequência no Gráfico 3 se relacionava a uma questão de múltipla escolha, portanto, o total foi superior a quantidade de questionários aplicados.

Gráfico 3: Distribuição de frequência quanto ao local em que mais acessa a internet

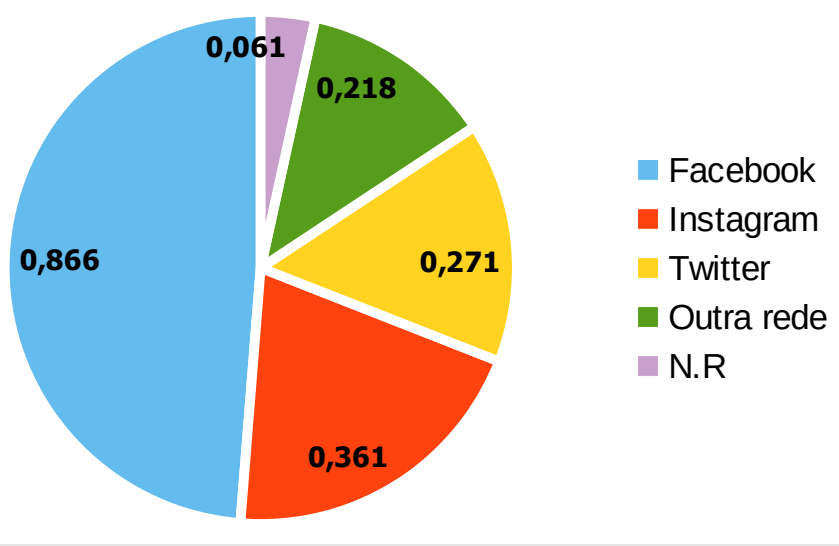

Fonte: Elaborado pelas autoras

Como pode ser constatado no Gráfico 4, do total de respondentes, $78,10 \%$ dos alunos responderam que gostariam que fosse criada uma página de Ciências no Facebook, enquanto $16,60 \%$ responderam que não. Alguns alunos, inclusive, responderam que 0 Facebook não era local para estudar. Esses dados nos indicaram que os alunos consideravam o Facebook como um meio possível para um trabalho pedagógico diferenciado.

Gráfico 4: Quanto a criação de uma página no Facebook para a aula de Ciências, se iria ajudar nas aulas

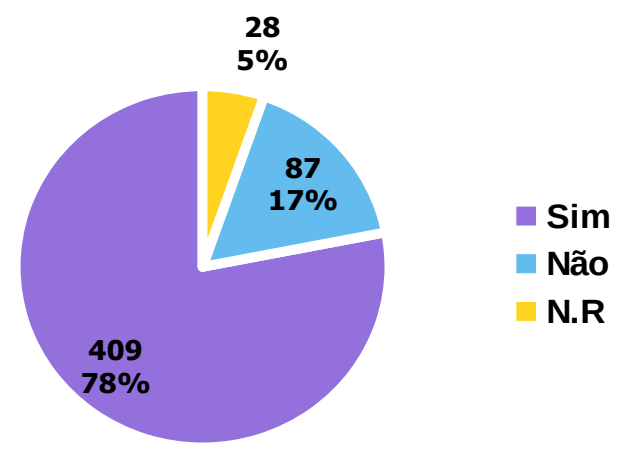

Fonte: Elaborado pelas autoras 
DOI: $10.12957 / \mathrm{e}-\mathrm{mosaicos} .2021 .49852$

A maioria dos alunos nas horas vagas acessavam as redes sociais $(50,80 \%)$, navegavam na internet (44,50\%), escutavam música (44,30\%) e assistiam televisão $(38,40 \%)$ entre outras atividades, como pôde ser verificado em outra pergunta dessa pesquisa.

Finalmente, em 30 de outubro de 2017 foi dado início à criação do grupo de estudos de ciências na escola em Manguinhos. Inicialmente, foi distribuído pela escola um convite aos alunos com o link para entrada na página do grupo. Na época, havia 35 alunos interessados no grupo e participando por meio de visualizações, comentários e curtidas nas postagens relacionadas a ciências. Houve também o pedido de ingresso do perfil de mães que gostariam de entrar no grupo. Toda a entrada se dava por meio de um questionário inicial perguntando se o usuário era aluno da escola ou algum parente e, com isso, era autorizada a entrada ou não. Assim, foi verificado que a rede social pode potencializar situações que gerem interesse, questionamentos e reflexões dos alunos sobre os temas das ciências, possibilitando que os alunos se apropriam do Facebook como uma ferramenta pedagógica que desperta mais interesse em pesquisar assuntos da disciplina de ciências.

\section{CONCLUSÃo}

Um dos grandes desafios para o (a) professor (a) na atualidade encontra-se em suscitar o interesse do estudante para aprender e dar sentido ao que é aprendido na escola. Apesar de todas as dificuldades em termos de infraestrutura física, de trabalho e de incentivo profissional e financeiro, o profissional procura meios para estimular 0 educando para a busca do conhecimento e fazer deste um significado para a formação dos seus valores e, dessa forma, fazer uma educação com qualidade.

Nessa perspectiva, as ações que foram realizadas tiveram como propósito promover práticas diferenciadas no ensino de ciências, contribuindo para a articulação dos conteúdos formais apresentados na sala de aula com a rede social Facebook e a biblioteca escolar. Nesse sentido, foi possível averiguar que estas se apresentam como ferramentas que facilitam o processo de ensino aprendizagem e contribuem para uma educação emancipadora e para a formação crítica dos alunos, dando possibilidades para que ressignifiquem o papel da biblioteca no contexto da escola e do uso das mídias para uma contextualização de sua realidade e se apoderem para transformar sua realidade.

A tentativa de se trabalhar o conhecimento em ambientes tão distintos, mas complementares, visando contribuir para a prática do professor e no processo de ensino aprendizagem dos alunos se deve ao fato de que a ação educativa não acontece apenas na sala de aula ou no ambiente escolar. Tornar o ensino de Ciências algo prazeroso e mais convidativo tem sido o objetivo de vários educadores e, compartilhando desse 
DOI: $10.12957 / \mathrm{e}-\mathrm{mosaicos} .2021 .49852$

pensamento, foi realizado esse estudo no intuito de ser a base para novas ações que foram posteriormente realizadas em continuação à pesquisa, levando-se em conta a realidade e as necessidades e gostos dos alunos.

Portanto, estas ações devem ser vistas como prioridade, coadunando interesses sociais e formativos para uma melhor qualidade de ensino e educação para a formação plena do cidadão. Com isso, se faz necessária uma atenção maior para as atividades transdisciplinares que busquem qualificar melhor e de forma plena os cidadãos envolvidos, a fim de implementar uma contínua capacitação e atualização mediante estudos aprofundados sobre temáticas relevantes à formação do estudante.

\section{CONSIDERAÇões Finais}

Este trabalho apresentou a descrição e resultados iniciais de uma pesquisa que foi realizada em uma escola pública municipal localizada em Manguinhos na cidade do Rio de Janeiro, caracterizada como uma comunidade vulnerável socialmente. Para tanto, o propósito foi levantar dados e apresentar características da realidade pesquisada, cujos resultados obtidos, por meio da aplicação do questionário, pôde direcionar e ajudar a verificar as possibilidades e limites do funcionamento da biblioteca e do hábito da leitura, como também serviram como indicadores quanto ao uso das redes sociais e sua utilização como uma ferramenta de apoio pedagógico.

O processo da pesquisa participante possibilitou entender que o questionário em questão contradisse o que foi apurado com relação à realidade dos alunos, pois o acesso e interação realizados com o Facebook eram de baixa assiduidade. Foi possível perceber que os alunos demonstravam a necessidade de não se apresentar como indivíduos excluídos da sociedade de consumo, diante da obtenção de produtos e equipamentos tecnológicos próprios. Outrossim, ressalta-se que, nessa experiência e nesse contexto, para que essas tecnologias pudessem trazer contribuições significativas, era preciso que fossem superados os vários aspectos desfavoráveis que estavam envolvidos, como a limitação de acesso à internet e de aquisição de aparelhos em bom estado e com capacidade de memória disponíveis tanto por parte dos alunos como da própria escola. Logo, é preciso, em pesquisas desse porte, analisar o contexto escolar em que se enquadram os alunos, uma vez que não se tem como estimular ou atuar com tecnologia, no qual os alunos, em sua grande maioria, não têm acesso aos equipamentos necessários como parte do seu cotidiano de vida.

Diante do exposto, consideramos que uma escola com infraestrutura adequada pode possibilitar a utilização de recursos do impresso ao digital como contribuição para o processo de ensino e aprendizagem de ciências, visando à formação crítica e autônoma 
DOI: $10.12957 / \mathrm{e}-\mathrm{mosaicos} .2021 .49852$

dos indivíduos e atenuar o desinteresse e a dificuldade dos alunos para as aulas de ciências, principalmente, em um contexto de vulnerabilidade social.

\section{REFERÊNCIAS}

ABRAMOVAY, M. et al. Juventude, violência e vulnerabilidade social na América Latina: desafios para políticas públicas. Brasília: UNESCO, 2002.

ADORNO, T. W.; HORKHEIMER, M. Dialética do esclarecimento: fragmentos filosóficos. Rio de Janeiro: Jorge Zahar, 1947.

CHASSOT, A. Alfabetização científica: questões e desafios para a educação. 5. ed., rev. Ijuí (RS): Unijuí, 2011.

FERREIRA, N. S. de A. As pesquisas denominadas "estado da arte". Educação \& Sociedade, v. 23, n. 79, 2002

FREIRE, P. A importância do ato de ler: em três artigos que se completam. 23. ed. São Paulo: Cortez Autores Associados, 1989.

GLOBO.COM. Lei que prevê biblioteca em cada escola está longe de ser cumprida. 2017. Disponível em: https://globoplay.globo.com/v/6245421/\#GLOBOPLAY-LATERALNOTICIAS-item-sel-9,rec-coldstart-section,37057390849. Acessado em: 2 jun. 2019.

INSTITUTO NACIONAL DE ESTUDOS E PESQUISAS EDUCACIONAIS ANÍSIO TEIXEIRA. Censo Escolar da Educação Básica: notas estatísticas. Brasília: MEC; Inep, 2017. Disponível em: http://download.inep.gov.br/educacao_basica/censo_escolar/notas_estatisticas/2017/ notas_estatisticas_censo_escolar_da_educacao_basica_2016.pdf . Acesso em 2 jun. 2019.

MARCUSE, H. A ideologia da sociedade industrial. 4. ed. Rio de Janeiro: Zahar Editores, 1973.

MINISTÉRIO DA EDUCAÇÃO. Lei $n$ 12.244, de 24 de maio de 2010. Dispõe sobre a universalização das bibliotecas nas instituições de ensino do País. Brasília: Diário Oficial [da] República Federativa do Brasil, 2010.

OLIVEIRA, C. A. D. Considerações primeiras sobre o ensino de Língua Portuguesa por máquina. Texto e ensino. São Paulo: Cabral, p. 179-200, 2002. 
DOI: $10.12957 / \mathrm{e}-\mathrm{mosaicos} .2021 .49852$

OLIVEIRA, M. A. D.; OLIVEIRA, J. N. V. D. Mídia e educação no universo escolar: discutindo o uso do computador na prática pedagógica. Revista Eletrônica Científica Ensino Interdisciplinar, v. 3, n. 7, p. 103-113, 2017.

RADO, S. C.; BONETI, L. W. A juventude em condições de vulnerabilidade social e as políticas de acesso à educação. In IX Congresso Nacional de Educação-EDUCERE. III Encontro Sul Brasileiro de Psicopedagogia, p. 3607-3618, 2009.

SILVA, M. R. da.; HAYASHI, C. R. M.; HAYASHI, M. C. P. I. Análise bibliométrica e cientométrica: desafios para especialistas que atuam no campo. In CID: Revista de Ciência da Informação e Documentação, v. 2, n.1, p. 110-129, 2011.

SILVA, S. Redes Sociais Digitais e Educação. Revista Eletrônica-I/uminart, v. 1, n. 5, 2010.

Recebido em 02 de abril de 2020

Aceito em 17 de março de 2021

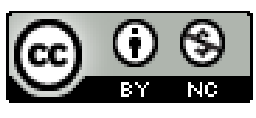

A e-Mosaicos Revista Multidisciplinar de Ensino, Pesquisa, Extensão e Cultura do Instituto de Aplicação Fernando Rodrigues da Silveira (CAp-UERJ) está disponibilizada sob uma Licença Creative Commons - Atribuição - NãoComercial 4.0 Internacional.

Os direitos autorais de todos os trabalhos publicados na revista pertencem ao(s) seu(s) autor(es) e coautor(es), com o direito de primeira publicação cedido à e-Mosaicos.

Os artigos publicados são de acesso público, de uso gratuito, com atribuição de autoria obrigatória, para aplicações de finalidade educacional e não-comercial, de acordo com o modelo de licenciamento Creative Commons adotado pela revista. 